\title{
Identification of the building parameters that influence heating and cooling energy loads for apartment buildings in hot-humid climates
}

\author{
Yusuf Yıldız ${ }^{1}$, Zeynep Durmuş Arsan* \\ Izmir Institute of Technology, Department of Architecture, Gülbahçe Köyü, Urla, TR-35430, Izmir, Turkey
}

\section{A R T I C L E I N F O}

\section{Article history:}

Received 18 September 2010

Received in revised form

16 March 2011

Accepted 8 April 2011

Available online 8 May 2011

\section{Keywords:}

Building parameters

Energy performance

Sensitivity and uncertainty analyses

Apartment buildings

\begin{abstract}
A B S T R A C T
Identifying the building parameters that significantly impact energy performance is an important step for enabling the reduction of the heating and cooling energy loads of apartment buildings in the design stage. Implementing passive design techniques for these buildings is not a simple task in most dense cities; their energy performance usually depends on uncertainties in the local climate and many building parameters, such as window size, zone height, and features of materials. For this paper, a sensitivity analysis was performed to determine the most significant parameters for buildings in hot-humid climates by considering the design of an existing apartment building in Izmir, Turkey. The Monte Carlo method is selected for sensitivity and uncertainty analyses with the Latin hypercube sampling (LHC) technique. The results show that the sensitivity of parameters in apartment buildings varies based on the purpose of the energy loads and locations in the building, such as the ground, intermediate, and top floors. In addition, the total window area, the heat transfer coefficient (U) and the solar heat gain coefficient (SHGC) of the glazing based on the orientation have the most considerable influence on the energy performance of apartment buildings in hot-humid climates.
\end{abstract}

(c) 2011 Elsevier Ltd. All rights reserved.

\section{Introduction}

Energy requirements, especially of the residential building sector, are an important part of the total energy consumption in many countries. For example, in Turkey, the building sector was the second largest consumer of energy with 25.793 million tons of equivalent energy (MTOE) in 2001, and its demand is estimated to reach 41.7 MTOE by 2020 [1]. This is the eventual result of the noteworthy increase in the demand for new buildings and apartment buildings. Another reason for the high energy consumption of the building sector may be related to inadequate energy conservation measures in some buildings due to uncontrolled urbanization and building construction activities. According to Kayıkçı [2], there are 2.5 million unregistered dwellings in Turkey, and no measures whatsoever for energy efficiency are under consideration for these buildings. Until now, this increasing energy demand has been covered by increasing the energy supply from other countries. However, one of the common methods applied by northern

\footnotetext{
* Corresponding author. Tel.: +90 232 7507020; fax: +90 2327507012.

E-mail addresses: yusifyildiz@gmail.com (Y. Yıldız), zeynepdurmus@iyte.edu.tr (Z.D. Arsan).

1 Tel.: +90 232750 7156; fax: +90 2327507012 .
}

countries to reduce energy consumption is the policy of enforcing energy efficiency in the building sector.

The residential districts of fast-growing southern cities usually consist of apartment buildings that accommodate many people. Izmir, a commercial harbor city, is one example of a densely populated city in which a high proportion of the population lives in apartment blocks in attached or detached order, depending on the local master plan decisions in use. The application of the optimum shape and orientation and other passive design techniques to improve the energy efficiency of apartment buildings in more densely populated areas may not always be possible or easy. However, an existing study has demonstrated that the improvement of energy performance in buildings is possible by focusing on appropriate building parameters, despite the negative effect of mandatory decisions [3]. It has been demonstrated that the important decisions about the energy profile of a building are mostly related to its building parameters. Thus, determining the suitable values of the most significant, i.e., the most sensitive, building parameters can reduce the energy consumption in apartment buildings.

This paper concentrates on determining the building parameters that have the most significant impact on the annual heating and cooling energy loads so that we may know which parameters should be adjusted to obtain the greatest reduction in energy consumption in hot-humid climates. In addition, the uncertainty in annual heating and cooling energy loads is investigated, depending 
on the variability of the selected building parameters. While uncertainty analysis in the early stages of building design shows the possible top and bottom ranges in annual heating and cooling energy loads, sensitivity analysis is a complementary tool to enable the architectural decision making process to further benefit from the design stage. For this reason, global uncertainty and sensitivity analyses are conducted together on a plan of an existing apartment building that is subject to the climatic conditions of Izmir, i.e., a hothumid climate.

\section{Building parameters that influence energy consumption}

Though architects have relatively limited information about the effects of building parameters on energy performance in the early stages of building design, they have to deal with several uncertain and sensitive parameters. Some of these parameters are summarized in Table 1 [4].

Making early architectural design decisions, including integrating the optimal values of these building parameters depending on the climatic conditions and building types, is an important task during the design process of buildings because the design team has various degrees of freedom for choosing building parameters. Climatic conditions are independent criteria that are impossible for people to control. In addition, it affects amount of the energy consumption in buildings [5]. Decisions that neglect the local climatic conditions in the design process of buildings can lead to increased energy requirements. However, a significant amount of energy for heating and cooling may be saved by following simple heat transfer principles and selecting suitable values for the most sensitive building parameters. Therefore, identifying the influence of building parameters on a building's energy performance can support the decision-making process during the architectural design steps. Otherwise, the design team must rely on the performance of active components, e.g., heating, cooling, ventilating and lighting systems, which are usually chosen in the late design stage. Another essential point is that effects of these parameters should be known in the earlier stages of architectural design, because later attempts to improve the energy performance constitute a loss of opportunity for a more cost-effective solution (Fig. 1).

Knowing which parameters are most important is essential for developing efficiency in the design process of apartment buildings that have high energy performance and also for supporting policy makers in the development of local energy-efficient design rules and limits based on the climatic conditions.

There are various studies that deal with the definition of sensitive building parameters for the energy performance of especially office buildings. It was determined by de Wit [7] that the parameters that have an important influence on the thermal comfort in naturally ventilated office buildings. Andarini et al. [8] defined the most sensitive parameters for reducing the cooling energy requirements in small office buildings. Heiselberg et al. [9] concentrated on the implementation of a sensitivity analysis to design sustainable buildings and found significant parameters that are important for decreasing the primary energy consumption of selected buildings. Badescu et al. [10] studied on the first Romanian passive office building and performed a local sensitivity analysis to find impact of thickness of insulation on external wall and roof, lighting, heat released by habitants and set point temperature for cooling. The results presented that thickness of the insulation on external wall and roof and also electric lighting do not have considerable effect on the cooling loads. Set point temperature for cooling has a considerable impact on cooling loads. Mechri [11] identified the design variables that have the greatest impact on the variation of building energy consumption. In addition, the contribution of each design parameter to the building's energy performance was investigated in a typical office building. Schicktanz et al. [12] analyzed the primary energy consumption and the economic applicability of a combined heating, cooling and power (CHCP) system in Germany and found that energy prices and the electric efficiency of the combined heating and power unit are dominant factors affecting its performance. Dominguez-Munoz et al. [13] applied sensitivity analysis to find key factors for the calculation of peak cooling loads in buildings. It is clear that previous studies usually concentrated on office buildings. Thus, there is a need for research that focuses on the parameters affecting the energy performance of apartment buildings.

\section{Methodology and materials}

This section provides a detailed description of the methodology used to identify the most influential parameters and to analyze variations in annual heating and cooling energy loads depending on uncertainties in selected parameters in apartment buildings in hothumid climates. First, the plan of an existing typical apartment building is selected for which the uncertainty and sensitivity analysis methods will be performed, and basic climatic features of Izmir are defined. Then, the selected methods are explained, and the investigated building parameters are selected. Lastly, the uncertainty and sensitivity analyses are applied.

\subsection{Base-case building and climate}

A 10-storey apartment building in Izmir, Turkey is selected as a reference building to implement the uncertainty and sensitivity analyses. As a fundamental input for setting design variables of a sensitivity analysis, the defined base case building is considered as a generic example in hot-humid climates in Turkey, representing common building materials and construction techniques for walls, floors and openings, and architectural features.

The basic geographic and climatic features of Izmir are as follows [14]:

Table 1

Design parameters based on the different design stages [4].

\begin{tabular}{|c|c|c|}
\hline Predesign & Schematic design & Design development \\
\hline Orientation & Windows area for detailed analysis & Different heating systems \\
\hline Floor plan depth & Glazing type & $\begin{array}{l}\text { Different heating control } \\
\text { strategies }\end{array}$ \\
\hline Space usage & Shading and/or blinds & Different cooling systems \\
\hline Windows area & Blind and/or shading control & Different cooling control strategies \\
\hline $\begin{array}{l}\text { U values for opaque and } \\
\text { transpired surfaces }\end{array}$ & Exact orientation & Different ventilation control strategies \\
\hline Light/heavy construction & Exact air change rate & \\
\hline Air change rate & Material adjustment in overheating areas & \\
\hline Heat recovery system & Cooling required: yes/no & \\
\hline Fuel type & Lighting strategy & \\
\hline
\end{tabular}




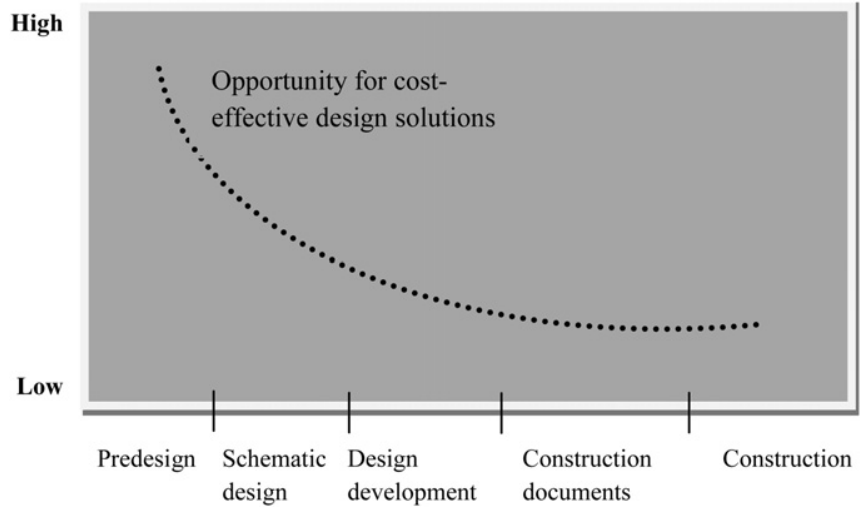

Fig. 1. Impact of inputs on building performance [6].

- $38^{\circ} 25^{\prime}$ North latitude and $27^{\circ} 09^{\prime}$ East longitude.

- Altitude of $4 \mathrm{~m}$ above sea level.

- The minimum mean and maximum mean temperatures are $5.7^{\circ} \mathrm{C}$ and $33^{\circ} \mathrm{C}$ for the months of January and July.

- The annual mean global radiation is $4.1 \mathrm{kWh} / \mathrm{m}^{2}$-day.

- The prediction of the annual degree-days is $1361\left(19{ }^{\circ} \mathrm{C}\right)$ for heating and $360\left(23^{\circ} \mathrm{C}\right)$ for cooling.

The reference building is also representative of the low-rise apartment blocks to be constructed in the near future in Izmir, and thus its location and orientation are not fixed (Fig. 2).

The building has a rectangular base $(23.3 \mathrm{~m}$ and $24.6 \mathrm{~m}$ ) and consists of four flats in each storey. The height of each flat is $3 \mathrm{~m}$ and the total height of the apartment building is $30.7 \mathrm{~m}$. The area of the flats is approximately $130 \mathrm{~m}^{2}$, which gives a total heated floor area of $520 \mathrm{~m}^{2}$ for each storey. The apartment building satisfies all minimum mandatory conditions defined in TS 825- Thermal Insulation Regulation in Buildings [15]. Therefore, the external walls are composed of a $20 \mathrm{~mm}$-thick outer layer of plaster, a $30 \mathrm{~mm}$-thick thermal insulation layer (XPS), a $190 \mathrm{~mm}$-thick layer of hollow brick and a $15 \mathrm{~mm}$-thick internal layer of plaster with an overall Uvalue of $0.606 \mathrm{~W} / \mathrm{m}^{2} \mathrm{~K}$. The overall $\mathrm{U}$-values of the ceiling and ground floors are 0.42 and $0.65 \mathrm{~W} / \mathrm{m}^{2} \mathrm{~K}$. The windows consist of low-e glazing glass panes with an overall U-value of $2.76 \mathrm{~W} / \mathrm{m}^{2} \mathrm{~K}$.

Three thermal models representing the ground, intermediate and top floors are generated for the reference building because each floor has a different energy performance. Each floor has two main thermal zones. Zone 1 is the core of floor including staircase, which is modeled as an unoccupied zone. Zone 2 is the rest of floor covering all flats (Fig. 2). In addition, color of the external walls and roof surface are evaluated by using solar absorptance value in the study. In the reference building, geothermal energy is used for heating and cooling is provided by a split air conditioner, but it is assumed that the reference building has a central system for cooling in the present study because defining a schedule for individual cooling or heating systems based on the behavior of occupants who live in different flats is not an easy task. The effects of the behavior of the occupants on energy performance will be taken into account in a later study.

\subsection{Uncertainty and sensitivity analysis}

A sensitivity analysis is performed to determine the most important parameters in apartment buildings that are located in hot-humid climates. In addition, uncertainty analysis is used to

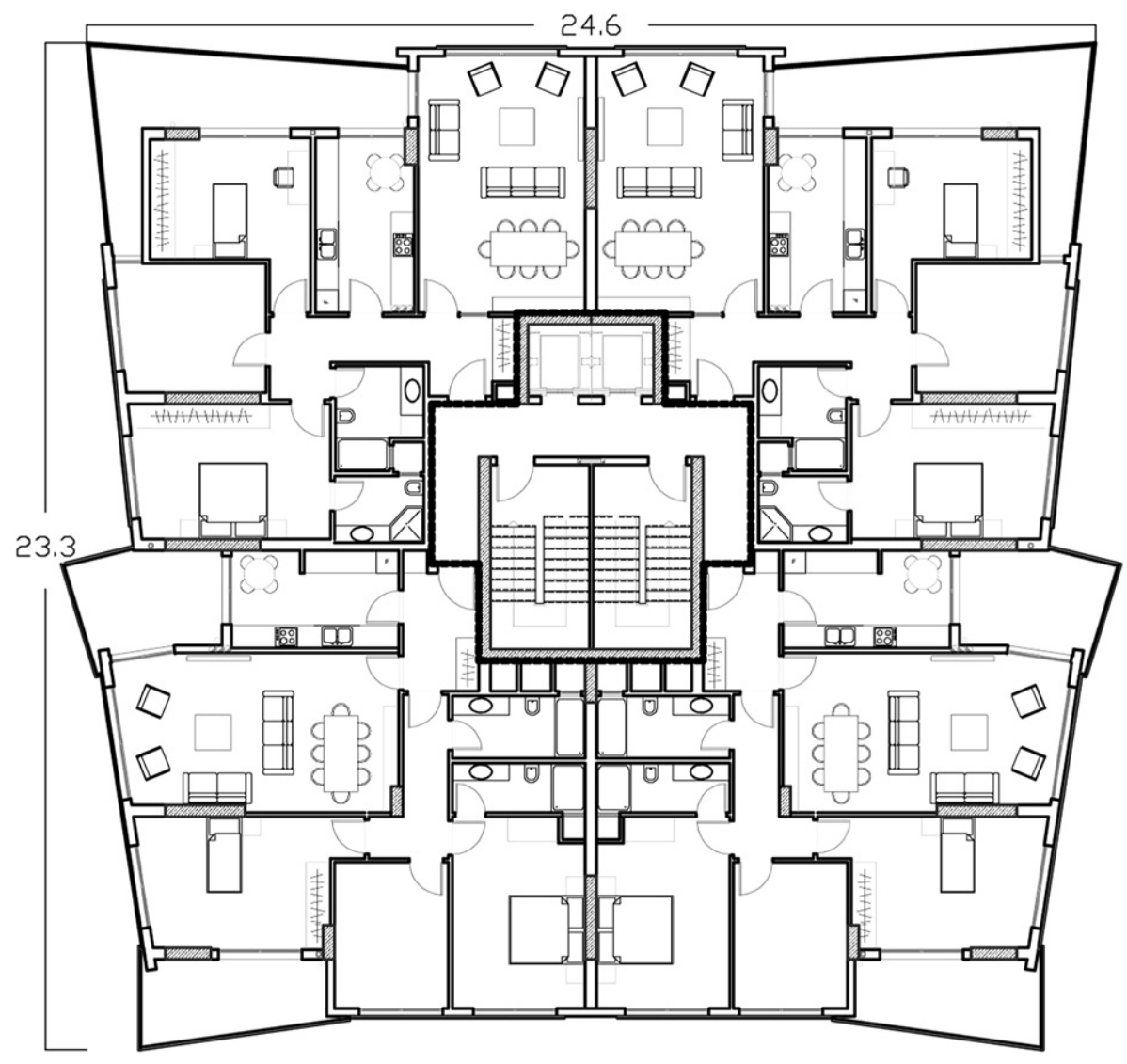

Fig. 2. Typical floor plan of selected apartment building. 
evaluate possible variations in the annual heating and cooling energy loads. In this study, it is considered that uncertainty in building parameters arises from the variety in several parameters in the building sector of Turkey, such as the exact properties of materials, occupancy decisions such as set point temperatures, and architectural decisions such as window areas.

While uncertainty analysis determines the possible range in the outputs of the model due to uncertainties in the input variables [16-18], sensitivity analysis is a common technique for investigating, both qualitatively and quantitatively, how the uncertainty in the model outputs is attributed to different sources of variation in the inputs [19]. In addition, it defines the influence of the individual design components on the total performance of the models in general [9].

There are three common types of methods that are used to conduct sensitivity analysis, the screening, local and global methods, which can all be applied by using building thermal analysis programs. The screening method is necessary in various models that require a large number of input factors. The main objective of this method is to compile a short list of important factors for further steps [19]. It is applied before global sensitivity analysis to save time. Local sensitivity analysis evaluates the output variability by changing one design parameter while all others are kept constant [20]. This method can be easily compared to global sensitivity analysis. One of the disadvantages is that the input parameters are assumed to be linear and their impacts are superimposed to obtain the total uncertainty [21]. Global sensitivity analysis investigates the effects of all the inputs at once. In other words, it can be used to quantify the influence of uncertain input parameters on the response variability of a model [22]. In this paper, Monte Carlo analysis (MCA), which is one of the current global sensitivity analysis techniques, is selected because the sensitivity of selected parameters can change based on the interactions and effects of all parameters, and the minimum number of simulations is sufficient to apply this method [9,23]. In addition, MCA is useful for building thermal simulations, and it can be implemented for both uncertainty and sensitivity analyses [24,25]. The MCA will result on a vector output which consists of $n$ element $[Y]=\left(y_{1}, y_{2}, \ldots, y_{n}\right)$. It can be summarized with the expectation $(E)$ and the variance $(V)$ of the output $Y$ calculated by the below expressions where $n$ is the number of elements [21]:

$E(Y)=\frac{1}{n} \sum_{i=1}^{N} y_{i}$

$V(Y)=\frac{1}{n-1} \sum_{i=1}^{N}\left[y_{i}-E(Y)\right]^{2}$

Square root of the variance also gives the standard deviation. MCA is a so-called black box approach; extra code modification is not necessary. Therefore, it can be performed easily. In this research, sensitivity and uncertainty analysis are applied by following five steps.

\subsubsection{Determination of output variables}

First, the annual heating and cooling energy loads are assigned as output variables because these are significant and common indicators of the energy performance and level of energy efficiency in buildings.

Table 2

Building parameters, their probability density functions and ranges.

\begin{tabular}{|c|c|c|c|c|}
\hline Building parameters & Unit & $\begin{array}{l}\text { Probability } \\
\text { density function }\end{array}$ & $\begin{array}{l}\text { Min. } \\
\text { value }\end{array}$ & $\begin{array}{l}\text { Max. } \\
\text { value }\end{array}$ \\
\hline Length of building & $\mathrm{m}$ & Continues uniform & 12 & 22 \\
\hline Width of building & $\mathrm{m}$ & Continues uniform & 12 & 22 \\
\hline Set point temperature for heating (Heating set point $t$.) & ${ }^{\circ} \mathrm{C}$ & Continues uniform & 19 & 23 \\
\hline Set point temperature for cooling (Cooling set point t.) & ${ }^{\circ} \mathrm{C}$ & Continues uniform & 24 & 26 \\
\hline Air infiltration rate (Air infilt.) & ach & Continues uniform & 0.5 & 2 \\
\hline Natural ventilation rate (Natural vent.) & ach & Continues uniform & 0.5 & 4 \\
\hline Windows area: south & $\%$ & Continues uniform & 5 & 90 \\
\hline Windows area: north & $\%$ & Continues uniform & 5 & 90 \\
\hline Windows area: east & $\%$ & Continues uniform & 5 & 90 \\
\hline Windows area: west & $\%$ & Continues uniform & 5 & 90 \\
\hline U-value of window-South (U value:window-south) & $\mathrm{W} / \mathrm{m}^{2} \mathrm{~K}$ & Continues uniform & 1.1 & 2.9 \\
\hline U-value of window-North (U value:window-north) & $\mathrm{W} / \mathrm{m}^{2} \mathrm{~K}$ & Continues uniform & 1.1 & 2.9 \\
\hline U-value of window-East (U value:window-east) & $\mathrm{W} / \mathrm{m}^{2} \mathrm{~K}$ & Continues uniform & 1.1 & 2.9 \\
\hline U-value of window-West (U value:window-west) & $\mathrm{W} / \mathrm{m}^{2} \mathrm{~K}$ & Continues uniform & 1.1 & 2.9 \\
\hline SHGC of window-South & - & Continues uniform & 0.28 & 0.75 \\
\hline SHGC of window-North & - & Continues uniform & 0.28 & 0.75 \\
\hline SHGC of window-East & - & Continues uniform & 0.28 & 0.75 \\
\hline SHGC of window-West & - & Continues uniform & 0.28 & 0.75 \\
\hline Color of external walls-South (Color: ext. wall-south) & - & Continues uniform & 0.1 & 0.9 \\
\hline Color of external walls-North (Color: ext. wall-north) & - & Continues uniform & 0.1 & 0.9 \\
\hline Color of external walls-East (Color: ext. wall-east) & - & Continues uniform & 0.1 & 0.9 \\
\hline Color of external walls-West (Color: ext. wall-west) & - & Continues uniform & 0.1 & 0.9 \\
\hline Color of roof (Color: roof) & - & Continues uniform & 0.1 & 0.9 \\
\hline Space height & $\mathrm{m}$ & Continues uniform & 2.6 & 3 \\
\hline Specific heat of external wall & $\mathrm{J} / \mathrm{kg}-\mathrm{K}$ & Continues uniform & 800 & 990 \\
\hline Thickness of thermal insulation on external walls-South (Thickness: ins-ext. wall-south) & $\mathrm{m}$ & Continues uniform & 0.01 & 0.2 \\
\hline Thickness of thermal insulation on external walls-North (Thickness: ins-ext. wall-north) & $\mathrm{m}$ & Continues uniform & 0.01 & 0.2 \\
\hline Thickness of thermal insulation on external walls-East (Thickness: ins-ext. wall-east) & $\mathrm{m}$ & Continues uniform & 0.01 & 0.2 \\
\hline Thickness of thermal insulation on external walls-West (Thickness: ins-ext. wall-west) & $\mathrm{m}$ & Continues uniform & 0.01 & 0.2 \\
\hline Thickness of thermal insulation on roof (Thickness: ins-roof) & $\mathrm{m}$ & Continues uniform & 0.01 & 0.2 \\
\hline Thickness of thermal insulation on ground (Thickness: ins-ground) & $\mathrm{m}$ & Continues uniform & 0.01 & 0.2 \\
\hline Thermal conductivity of external wall (Thermal conduct.: ext. wall) & $\mathrm{W} / \mathrm{mK}$ & Continues uniform & 0.15 & 2.1 \\
\hline Thermal conductivity of thermal insulation on external wall (Thermal conduct.:ext. wall ins.) & $\mathrm{W} / \mathrm{mK}$ & Continues uniform & 0.028 & 0.052 \\
\hline Thermal conductivity of thermal insulation on roof (Thermal conduct.: roof ins.) & $\mathrm{W} / \mathrm{mK}$ & Continues uniform & 0.028 & 0.052 \\
\hline Thermal conductivity of thermal insulation on ground (Thermal conduct.: ground ins.) & $\mathrm{W} / \mathrm{mK}$ & Continues uniform & 0.028 & 0.052 \\
\hline
\end{tabular}




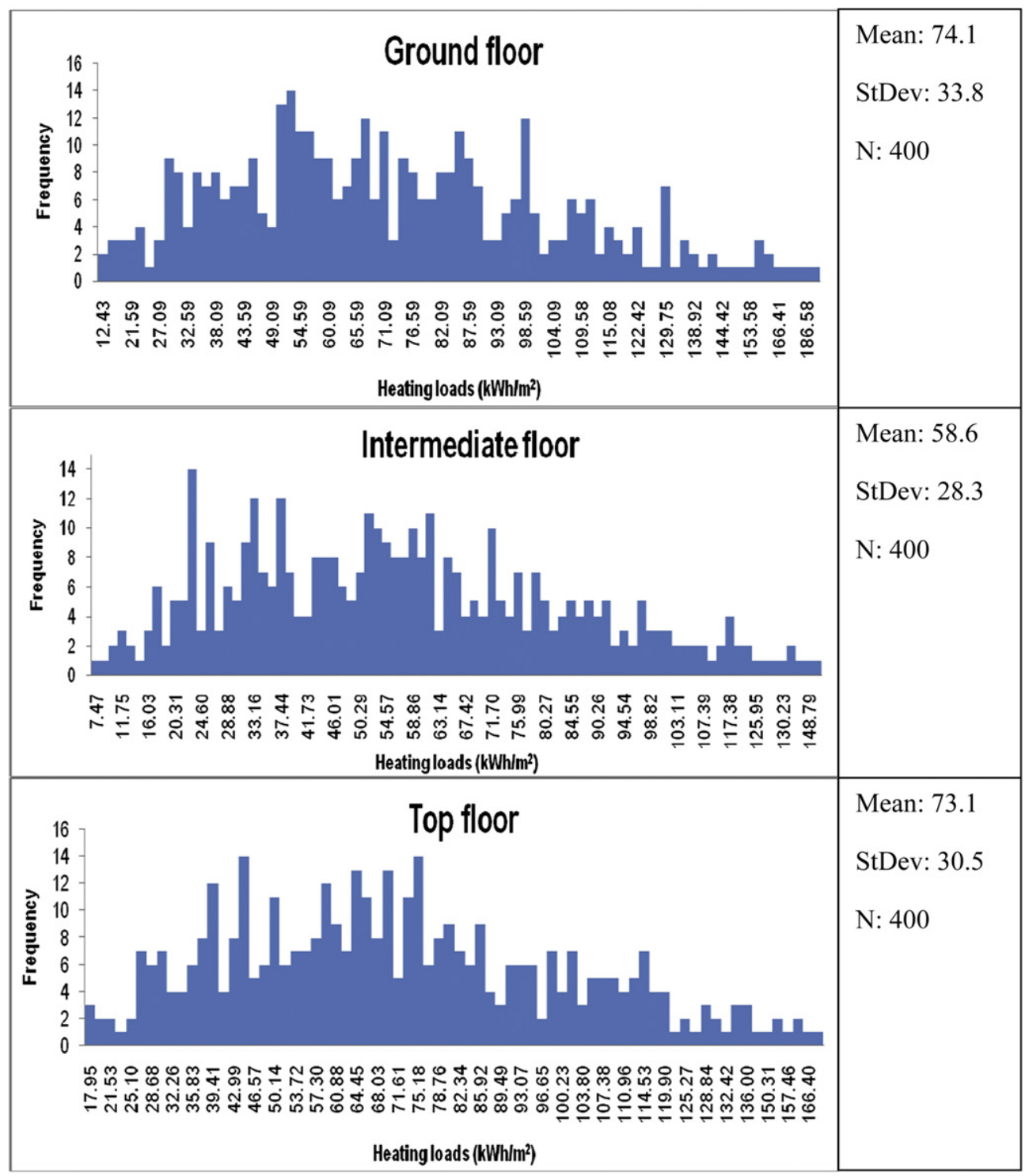

Fig. 3. Histogram of annual heating energy loads of apartment building.

\subsubsection{Determination of input parameters}

Nine simple and concise uncertain parameters in terms of architectural points of view have been selected and are assumed to be the main variables that influence the annual heating and cooling energy loads in apartment buildings: the building shape, the window-to-external-wall area, the envelope color, the set point temperature, the thermo-physical properties of building materials, the thermal insulation, the natural ventilation, the air infiltration and the zone height. They are also parameters that a design team can control. Then, 35 detailed building parameters are derived from the nine major parameters to support the decision-making process for improving the energy performance of apartment buildings. They are the length and width of the apartment building; the zone height; the set point temperatures for heating and cooling; the air infiltration rate; the natural ventilation rate; the window areas in the South, North, East, West directions; the U-value and solar heat gain coefficient (SHGC) of the windows based on their orientations; the thermal conductivity of main external wall material; the thermal conductivity of the thermal insulation material on the external wall, roof and ground; the specific heat of the external wall; the thickness of the thermal the insulation on external wall depending on the orientations; the thickness of the thermal insulation on the roof and ground; the color of the external wall based on the orientation and the color of the roof. The main difficulty with increasing the number of the selected building parameters in this study is mostly related to limitations of the simulation tool because each selected building parameter should be defined with one value in the software.

\subsubsection{Assignment of the probability density functions and the generation of a sample matrix}

The first part of the third step is to assign probability density functions to the 35 derived building parameters. The probability density functions, which can affect the results of the sensitivity analysis, were assumed to be uniform for all parameters shown in Table 2.

The minimum and maximum values for each parameter are essential for the definition of continuous uniform probability density functions. Therefore, minimum and maximum values are determined depending on the possibilities in architectural practice and technical limitations in Turkey's building sector. The upper and lower values of the parameters were interpreted as a central $95 \%$ confidence interval, and selection of values of all parameters is considered to be independent from any aesthetic concern, energy 


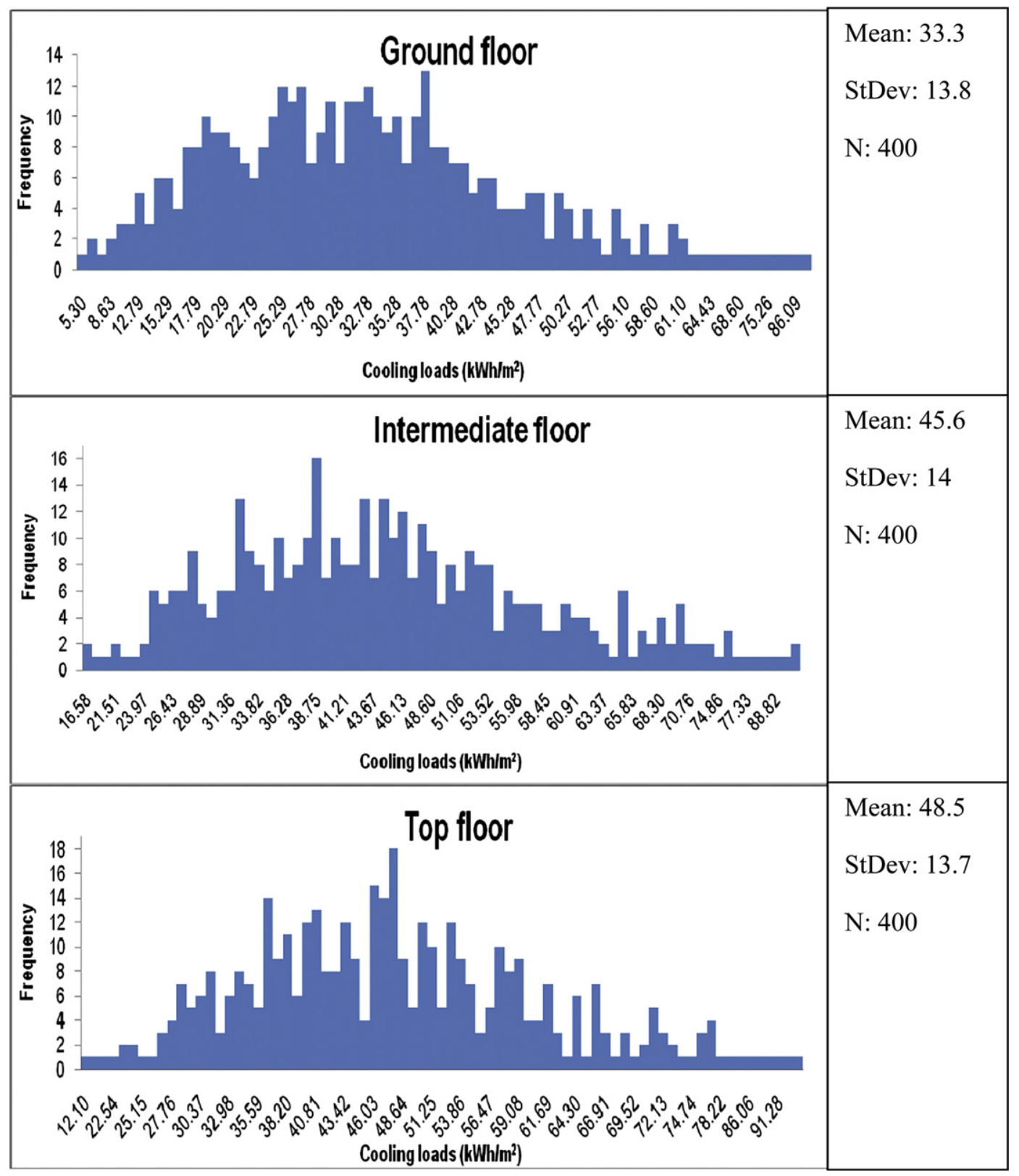

Fig. 4. Histogram of annual cooling energy loads of apartment building.

performance and compulsory codes to reflect real construction process in Turkey. This interpretation is important for evaluating and quantifying the significance of the parameters.

The second step of the third step is to generate a sample matrix. There are several sampling techniques that can be used in MCA studies. For this study, 400 samples for every building parameter were compiled based on the selected distribution by using the Latin hypercube sampling (LHS) method with SIMLAB 2.2, which is powerful free software for Monte Carlo-based sensitivity and uncertainty analyses [16]. The minimum number of generated samples should not be less than 1.5 times the number of uncertain inputs used in the model. Moreover, after processing 60-80 samples, the increase in the accuracy of the standard deviation is low in MCA [26,27]. Thus, the number of samples was chosen to be 400 to obtain a good accuracy in the sensitivity and uncertainty analyses. LHS is commonly used with computationally demanding models because its effective stratification features allow the extraction of a large amount of sensitivity with a relatively little sample size. It works by dividing the inputs into strata, and after generating samples, the value created for each parameter comes from a different stratum [28].

\subsubsection{Calculation of output variables}

Output variables corresponding to generated sample vectors were calculated with the EnergyPlus 5.0.0 simulation software [29]. This software was selected because it is free of charge, uses simple comma-separated ASCII txt files as input files and has been extensively validated. An EnergyPlus weather file (EPW) containing the general climatic features of Izmir was used for the weather data in all calculations.

\subsubsection{Selection of the indicator for the sensitivity}

The last step is to determine the sensitivity indicator to be used in the study. Different measures for sensitivity analysis are available in the SIMLAB software when generating samples with the LHC method. They are the Pearson Product Moment Correlation Coefficient (PEAR), 
Spearman Coefficient (SPEA), Partial Correlation Coefficient (PCC), Partial Rank Correlation Coefficient (PRCC), Standardized Regression Coefficient (SRC), and Standardized Rank Regression Coefficient (SRRC). They have different features depending on whether the relationships between input and output parameters are linear or nonlinear. For example, while PEAR is suitable for linear models, SPEA is preferred for non-linear models. SRC measures the linear impact of each input variable, while PCC provides a sensitivity analysis of systems that excludes the impact of correlations between input parameters. Here, SRRC, which can be used instead of SRC, was selected as an indicator to identify the sensitivity of each building parameter [16] because, like SRC, it is a quantitative measure of the sensitivity based on regression analysis; however, SRRC is calculated using a model covering rank transformation data [15].

\section{Results of the uncertainty and sensitivity analyses}

\subsection{Variations in annual heating and cooling energy loads: uncertainty analysis}

Annual heating and cooling energy loads per unit of flat area were calculated with MCA-LHS with a sample size equal to 400 . Thus, 1200 EnergyPlus simulations for the three stories are evaluated with histograms to present changes in the annual heating and cooling energy loads based on the uncertainties in the building parameters. Figs. 3 and 4 show the range of possible annual heating and cooling energy loads together with the frequency of each interval for the ground, intermediate, and top floors.

It is clear from these figures that the ranges in annual heating and cooling energy loads are different depending on the floor of the apartment building that is considered. In addition, the difference between the minimum and maximum annual heating/ cooling energy loads is relatively high. Therefore, building parameters should be arranged to provide high energy performance in apartment buildings in the early design stage because the difference between the minimum and maximum annual heating/cooling energy loads should not be too great with regulated building parameters.

While annual heating energy load is between 12.43 and $186.58 \mathrm{kWh} / \mathrm{m}^{2}$ on the ground floor, it is between 7.47 and $148.79 \mathrm{kWh} / \mathrm{m}^{2}$ on the intermediate floors and between 17.95 and $166.40 \mathrm{kWh} / \mathrm{m}^{2}$ on the top floor. The minimum energy for heating is on the intermediate floor, while the maximum demand is on the ground floor. The most frequent annual heating energy load is $54.59 \mathrm{kWh} / \mathrm{m}^{2}$ on the ground floor, $22.4 \mathrm{kWh} / \mathrm{m}^{2}$ on the intermediate floor, and $42.99 \mathrm{kWh} / \mathrm{m}^{2}$ on the top floor.

For annual cooling energy demand, the range is between 5.30 and $86.09 \mathrm{kWh} / \mathrm{m}^{2}$ on the ground floor and between 16.58 and $97.85 \mathrm{kWh} / \mathrm{m}^{2}$ on the intermediate floors. It varies between 12.10 and $98.24 \mathrm{kWh} / \mathrm{m}^{2}$ on the top floor. The ground floor requires the lowest amount of energy for cooling. The maximum energy consumption takes place on the top floor. The most frequent annual cooling energy load is $37.78 \mathrm{kWh} / \mathrm{m}^{2}$ on the ground floor, $39 \mathrm{kWh} / \mathrm{m}^{2}$ on the intermediate floor, and $48.24 \mathrm{kWh} / \mathrm{m}^{2}$ on the top floor.

Briefly, uncertainties in terms of annul heating energy is larger than uncertainties in terms of annual cooling energy. Depending on floors, while uncertainty in ground floor is larger than others for heating, it is close to each other in different floors for cooling.

The calculated minimum energy requirements for heating and cooling can be obtained by selecting the upper limit of the distribution for the building parameters that have a negative SRRC and by selecting the lowest limit of the distribution for building parameters that have a positive SRRC, as shown in the following section.

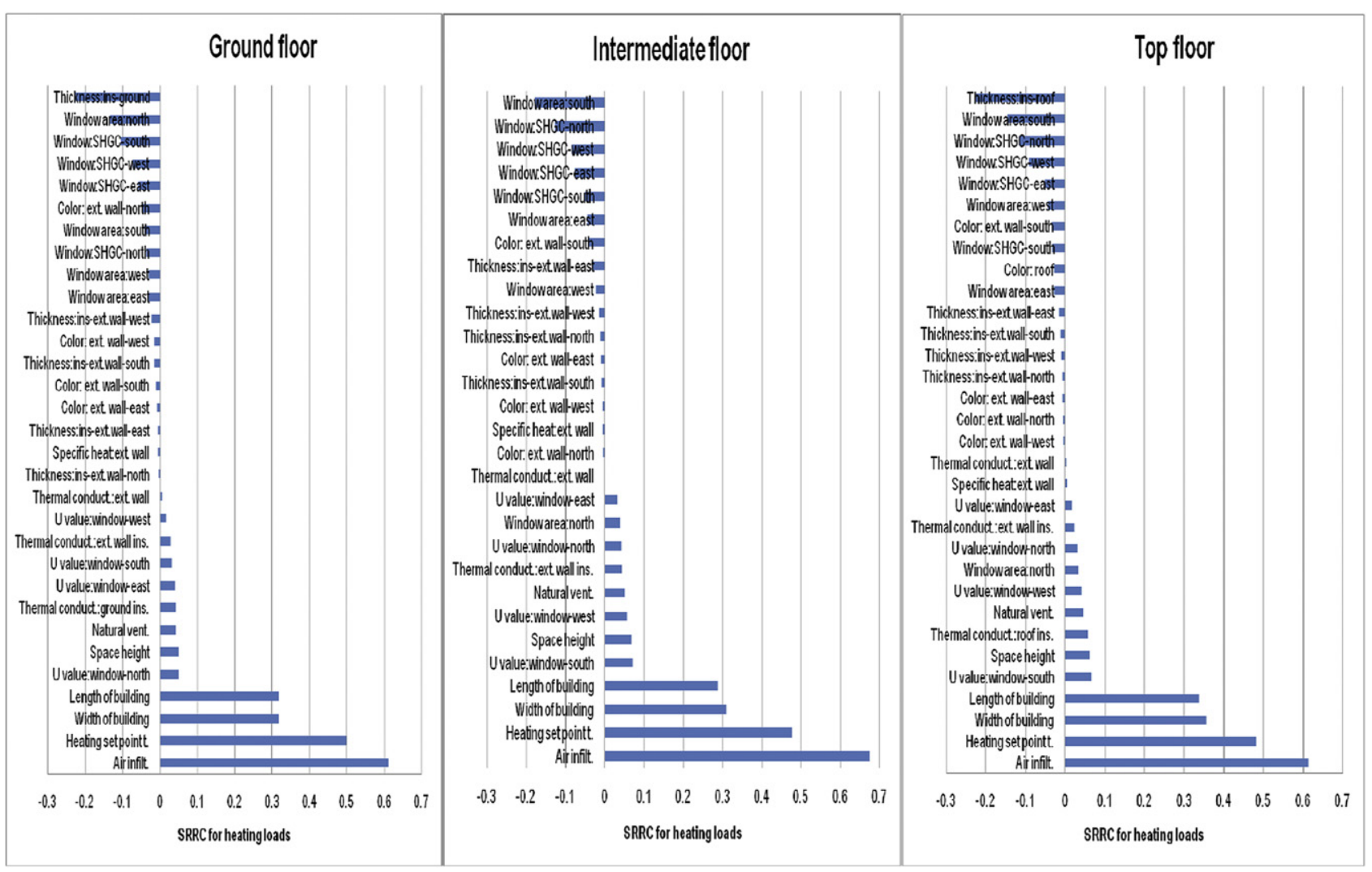

Fig. 5. Sensitivity index for selected building parameters: annual heating energy loads. 


\subsection{Building parameters that influence the heating and cooling energy loads: sensitivity analysis}

Figs. 5 and 6 present the sensitivity of each of the building parameters depending on the SRRC. A positive SRRC means that as the value of the building parameter increase, the value of the corresponding output simultaneously increases. A negative SRRC implies that changes in the inputs and outputs tend to go in opposite directions.

There is no considerable difference in the order of building parameters according to the level/floor considered. These changes should be considered as an expected outcome, for sensitivity of the same building components may change based on floors due to the several factors such as different amount of the energy consumption in different floors. In addition, ground floor may be more affected by ground temperature and thus thickness of the insulation material is one of the most important parameters in the ground floor. Moreover, top floor may be more affected by the roof heat transfer and thus thickness of the roof insulation material is one of the significant parameters. For that reason, differences in floors should not be considered that though some parameters in ground or intermediate or top floors are important, they are not important in other floors. It should be considered that all parameters are important. However, degree of the importance of the same building components can change in different floors.

For heating, the ten most important building parameters can be sorted as follows:

Ground floor: Air infiltration, heating set point temperature, width of building, length of building, thickness: ins-ground, window area: north, window: SHGC-south, window: SHGC-west, window: SHGC-east, and U value: north window.

Intermediate floor: Air infiltration, heating set point temperature, width of building, length of building, window area: south, window: SHGC-north, Window: SHGC-west, window: SHGC-east, $U$ value: south window, and space height.
Top floor: Air infiltration, heating set point temperature, width of building, length of building, thickness: ins-roof, window area: south, window: SHGC-north, window: SHGC-west, U value: south window, and space height.

For cooling, the ten most important building parameters are listed as follows:

Ground floor: Thickness: ins-ground, cooling set point temperature, natural ventilation, width of building, window area: east window area: west, length of building, window: SHGC-east, and window area: north.

Intermediate floor: Width of building, cooling set point temperature, window area: west, window area: east, length of building window area: south, natural ventilation, window: SHGC-west, window: SHGC-east, and window: SHGC-north.

Top floor: Width of building, cooling set point temperature, window area: west, length of building, window area: east, window: SHGC-west, window area: south, natural ventilation, window: SHGC-east, and window: SHGC-north.

South window related parameters such as "Window area: south and U value: window-south' in ground floor is less important than the same parameters in upper floors. Other parameters such as thickness: ins-ground is more important than south window related parameters in ground floor. Moreover, while the specific heat and thermal conductivity of main external wall material are the common parameters that have almost no effect on the annual heating energy load of the apartment building, the color of the external wall on the north side and the specific heat of the external wall do not affect the annual cooling energy load on the ground and intermediate floors of the apartment building. In addition, the Uvalue of the window on the south side and the thickness of the external wall on the north side are unimportant in terms of the cooling energy load on the top floor.

Based on the results of the sensitivity analysis, the following architectural points can be derived for apartment buildings in hothumid climates:

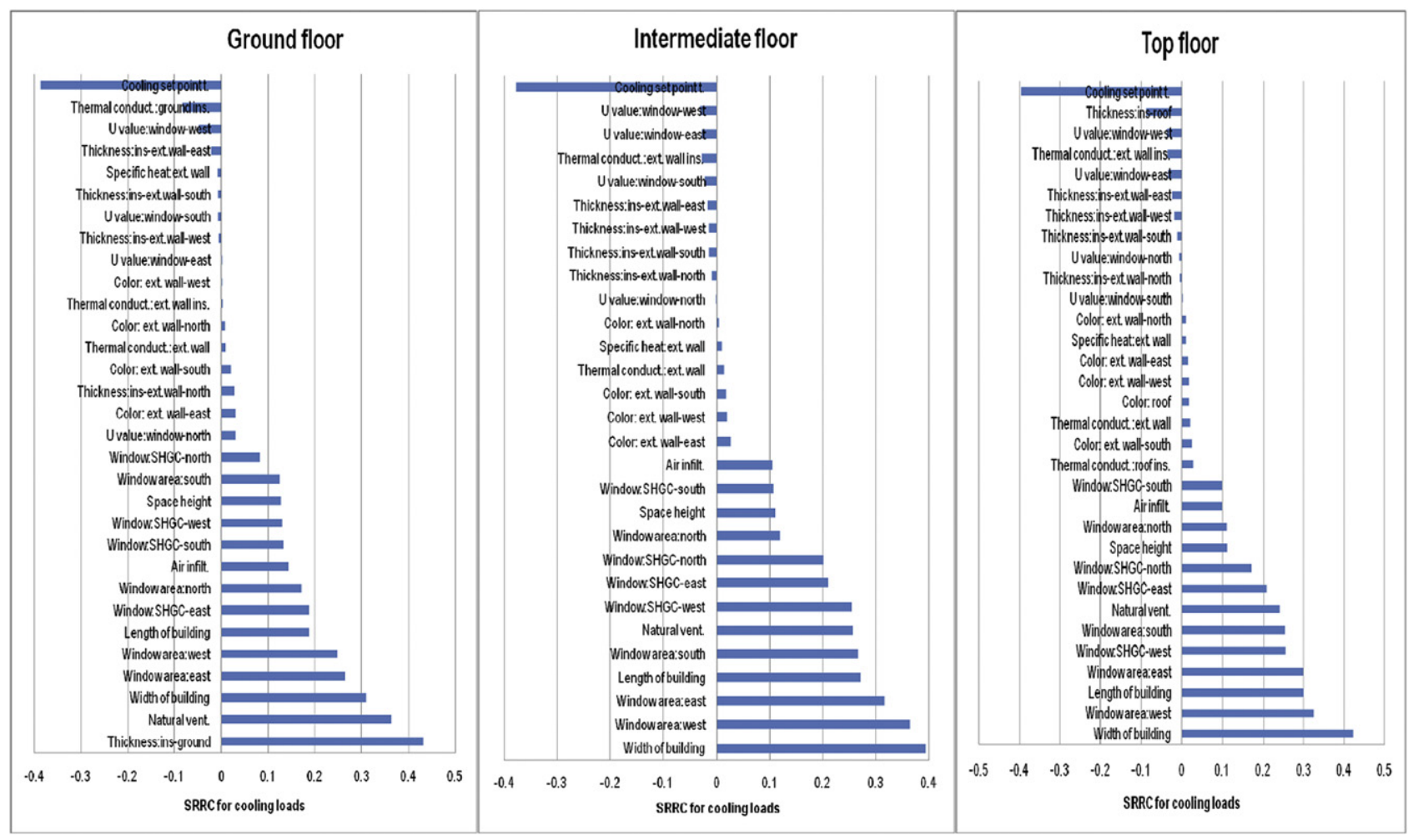

Fig. 6. Sensitivity index for selected building parameters: annual cooling energy loads. 
- In general, the orientation has an impact on the sensitivity of the building parameters for heating and cooling. Therefore, decision makers should develop different solutions for different orientations.

- Air tightness is important and should be high in the apartment buildings to reduce heating and cooling energy consumption.

- Variations in the set point temperatures depending on the habits of occupants can change the amount of the energy consumption for heating and cooling. Thus, optimum set point temperatures should be selected based on an occupant's thermal comfort range.

- The properties of glazing and window area are key variables. Thus, the SHGC, U-value of the window and its area should be determined according to the different orientations to increase the energy performance.

- Building shape is important for the energy consumption for heating and cooling because the aspect ratio, which is the ratio of the length of building to the width of building, has a deterministic role in the energy performance.

Our study shows that this information is particularly useful for design teams because they can decide easily which of the sensitive parameters are more important than the others based on the current conditions, such as the location of the apartment building in a densely populated city, during the design process to decrease the heating and cooling energy loads. Moreover, a design team can use time and money efficiently by not focusing on building parameters that have small effects.

\section{Conclusion}

This study showed the selected building parameters that are the most important and their possible ranges in terms of the annual heating and cooling energy loads in apartment buildings located in hot-humid climates by using sensitivity and uncertainty analyses. Our conclusions can be stated as follows, but it should not be forgotten that the results could vary for different climatic conditions [30].

1. Major architectural design solutions should be defined based on the dominant energy requirements in apartment buildings, because the sensitivity of building parameters varies depending on the heating and cooling energy loads.

2 . The minimum and maximum values of the energy requirements change according to which floor is considered. Thus, thermal models for buildings having more floors should be prepared by subdividing them into ground, intermediate and top floors to study the impacts of the building parameters. Such a procedure also provides feedback for clients selecting particular flats.

3. Sensitivity and uncertainty analyses can be used to improve the energy performance of apartment buildings at an early stage of the building design.

4. The annual heating and cooling energy loads are mostly affected by the features of the windows, such as the area, Uvalue, and SHGC depending on orientation in hot-humid climates.

5. The uncertainty in the annual heating and cooling energy loads is relatively high. Therefore, the importance of the sensitive building parameters is increased. Design team should focus on all of the most important parameters to increase the energy performance of apartment buildings in the early design stage.

6. The sensitivity of building parameters and possible ranges in annual heating and cooling energy demands for different climatic conditions can be defined easily by the process that is discussed in the present paper.

The findings of this study can provide more consciousness and flexibility for decision makers, i.e. designers, owners and users, in the early design process of apartment buildings in the hot-humid climate. Firstly, by considering considerable reductions in energy consumption, to know the most important parameters before the building is constructed can affect material, dimensional, functional or visual choices of decision makers in more energy-efficient way. Secondly, since the rate of seasonal energy consumption varies depending on ground, intermediate and top floors, it gives an opportunity to develop specific energy performance improvement and optimization strategies for particular lateral zones of apartment blocks, which provide at the end more flexibility in design of both building itself and its heating and cooling systems. As a result, early information provided by global uncertainty and sensitivity analyses is relevant for decision makers in architectural practice.

\section{Acknowledgements}

This study, which is conducted by the promoter of Dr. Z. D. ARSAN, is a part of an ongoing PhD research in Izmir Institute of Technology, Department of Architecture. We would like to thank the anonymous reviewers for their comments.

\section{References}

[1] Oğulata TR. Sectoral energy consumption in Turkey. Renewable and Sustainable Energy Reviews 2002;6:471-80.

[2] Kayıkçı M. Reinvestigation of case of slum [in Turkish]. Turkish Administration Journal 2004;443:105-18

[3] de Wilde P, Augenbroe G, van der Voorden M. Design analysis integration: supporting the selection of energy saving building components. Building and Environment 2002;37:807-16.

[4] Morbitzer C, Strachan P, Webster J, Spires B, Cafferty D. Integration of building simulation into the design process of an architecture practice. In: Proceedings of the 7th international IBPSA conference on building simulation, Rio de Janeiro, Brazil; August 13-15; 2001. p. 697-704.

[5] Lam JC, Wan KKW, Lam TNT, Wong SL. An analysis of future building energy use in subtropical Hong Kong. Energy 2010;35:1482-90.

[6] ASHRAE. ASHRAE green guide: the design, construction, and operation of sustainable buildings. Burlington: Elsevier Publications; 2006.

[7] de Wit MS. Uncertainty in predictions of thermal comfort in buildings. The Netherlands: Technical University Delft; 2001, Ph.D. thesis.

[8] Andarini R, Schranzhofer H, Streicher W. Energy simulation for atypical small office building in Indonesia. In: Proceedings of the first international conference on building energy and environment, Dalian China; August; 2008. p. 247-54. 4-6.

[9] Heiselberg P, Brohus H, Hesselholt A, Rasmussen H, Seinre E, Thomas S. Application of sensitivity analysis in design of sustainable buildings. Renewable Energy 2009;34:2030-6.

[10] Badescu V, Laaser N, Crutescu R. Warm season cooling requirements for passive buildings in southeastern Europe (Romania). Energy 2010;35: 3284-300.

[11] Mechri EH, Capozzoli A, Corrado V. Use of ANOVA approach for sensitive building energy design. Applied Energy 2010;87(10):3073-83.

[12] Schicktanz MD, Wapler J, Henning H-M. Primary energy and economic analysis of combined heating, cooling and power systems. Energy 2010;36:575-85.

[13] Dominguez-Munoz F, Cejudo-Lopez MJ, Carrillo-Andres A. Uncertainty in peak cooling load calculations. Energy and Buildings 2010;42(7):1010-8.

[14] Adnan Menderes Meteorological Station.

[15] Thermal insulation regulation in buildings. Ankara: Official Gazette (24043); 8 May 2000.

[16] SIMLAB. Version 2.2 simulation environment for uncertainty and sensitivity analysis. Developed by the Joint Research Center of the European Commission; 2004

[17] Ruijven van B, de Vries B, van Vuuren DP, Sluijs van der JP. A global model for residential energy use: uncertainty in calibration to regional data. Energy 2010;35:269-82.

[18] Houwing M, Ajah AN, Heijnen PW, Bouwmans I, Herder PM. Uncertainties in the design and operation of distributed energy resources: the case of microCHP systems. Energy 2008;33:1518-36.

[19] Saltelli A, Tarantola S, Campolongo F, Rotto M. Sensitivity analysis in practice: a guide to assessing scientific models. West Sussex: John Wiley \& Sons, Ltd; 2004. 
[20] Bojacá CR, Schrevents E. Energy assessment of peri-urban horticulture and its uncertainty: case study for Bogota, Colombia. Energy 2010;35:2109-18.

[21] Hopfe JC. Uncertainty and sensitivity analysis in building performance simulation for decision support and design optimization. The Netherlands: Eindhoven University of Technology; 2009. Ph.D. Thesis.

[22] Griensven Van A, Meixner T, Grunwald S, Bishop T, Diluzio M, Srinivasan R A global sensitivity analysis tool for the parameters of multi-variable catchment models. Journal of Hydrology 2006;324:10-23.

[23] Kim K, Von Spakovsky R, Wang M, Nelson D J. A hybrid multi-level optimization approach for the dynamic synthesis/design and operation/control under uncertainty of a fuel cell system. Energy 2010, doi:10.1016/j.energy. 2010.08.024.

[24] Breesch H, Janssens A. Performance evaluation of passive cooling in office building based on uncertainty and sensitivity analysis. Solar Energy 2010; 84(8):1453-67.
[25] Loutzenhiser PG, Maxwell GM, Manz H. An empirical validation of the daylighting algorithms and associated interactions in building energy simulation programs using various shading devices and windows. Energy 2007; 32:1855-70.

[26] Lomas KJ, Eppel H. Sensitivity analysis techniques for building thermal simulation programs. Energy and Buildings 1992;19:21-44.

[27] MacDonald I. Quantifying the effects of uncertainty in building simulation. UK: University of Strathclyde; 2002, Ph.D. thesis.

[28] Helton JC, Johnson JD, Sallaberry CJ, Storlie CB. Survey of sampling-based methods for uncertainty and sensitivity analysis. Reliability Engineering and System Safety 2006;91:1175-209.

[29] LBNL (Lawrence Berkeley National Laboratory). EnergyPlus manual V 5.0.0; November 2008. Berkeley.

[30] Zwaan van der B, Gerlagh R. Climate sensitivity uncertainty and the necessity to transform global energy supply. Energy 2006;31:2571-87. 